\title{
Estimation of the pull-off resistance models of reinforced concrete structures by a numerical method
}

\author{
Mikalai Shalabyta ${ }^{1 *}$,Elizabeth Matweenko ${ }^{1}$, Nikifor Matweenko ${ }^{1}$, and Valery Rakhuba ${ }^{1}$ \\ ${ }^{1}$ Brest State Technical University, Belarus
}

\begin{abstract}
Comparative analysis of calculations of calculation numerical models for pulling out embedded parts in reinforced concrete structures is carried out. Based on the results of numerical modeling, new information about the stress-strain state in reinforced concrete elements from the local action of the tensile force has been obtained.
\end{abstract}

\section{Introduction}

In the practice of designing reinforced concrete structures, ensuring strength under local action of tensile forces, except for the cases of work of special anchors, is carried out on the basis of compliance with certain design requirements obtained as a result of the operation of a number of structures.

Despite the aforementioned, in contrast to other types of destruction of reinforced concrete elements, the destruction by pulling off is less studied. Significant tensile forces applied in a relatively small area cause a special stress-strain state in the breakout zones, which depends on a large number of factors. As we noted in the article [9], in most of the standards for the design of reinforced concrete structures [3], the breakout calculation is envisaged only as ensuring the bearing capacity of structures with the purpose of increasing the length of anchoring of the breakout elements or to place additional reinforcement in the "conventional" breakout zone. In the calculations for breakout, regardless of the design situation, the shear resistance of concrete on the surface of the breakout prism is taken into account indirectly, estimating only the value of the breakout force with the bearing capacity of the breakouted element itself and additional (indirect) reinforcement [2]. The reduction in the amount of reinforcement in the breakout zone and reduction in the length of the anchoring, while taking into account the concrete tensile strength, will allow to reduce metal consumption, and therefore reduce the cost of the entire structure.

In order to assess the resistance of reinforced concrete elements under the local action of tensile forces, the peculiarities of the calculation and design of the currently most studied stress state in reinforced concrete structures, namely, the calculation of anchors, have been considered.

\footnotetext{
* Corresponding author: nnshalobyta@mail.ru
} 


\section{Calculation models}

Let us consider the basic conditions for the calculation of the action of the axial tensile force during destruction from concrete puling from the base, given in the norms [8], [11], [10], [7] using the example of embedded parts with normal anchors reinforced at the ends, according to the recommendations [9]. Table 1 shows analytical expressions and coefficients included in the formulae for evaluating the design models to determine the value of the resistance force for a single anchor, as well as the projection area of the conventional prism of concrete pulling out of the base (Figure 1).

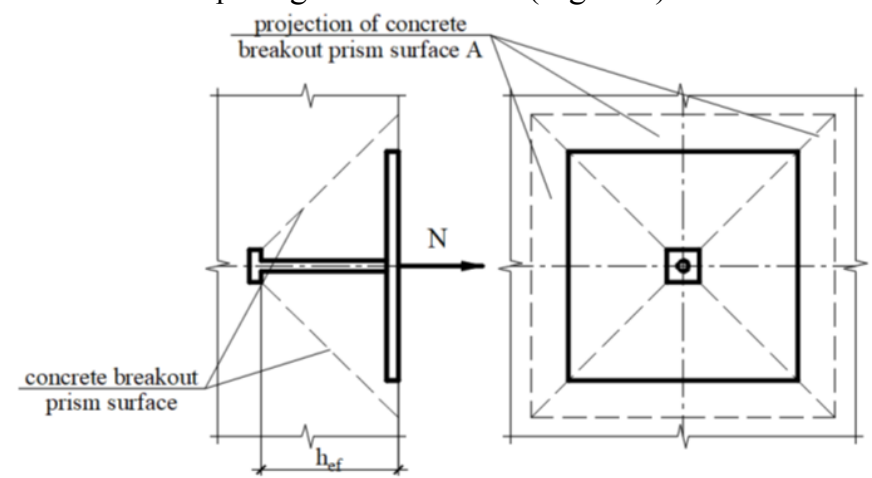

Fig. 1. Definition of the base of conventional prism of breakout under tension for a single anchor located at a significant distance from the edge of the base and the adjacent anchor.

Table 1. Estimation of computational models.

\begin{tabular}{|c|c|c|c|}
\hline $\begin{array}{c}\text { № } \\
\text { in } \\
\text { order }\end{array}$ & $\begin{array}{c}\text { Normative } \\
\text { document } \\
\text { type }\end{array}$ & Anchor resistance force & $\begin{array}{c}\text { Conventional } \\
\text { breakout prism } \\
\text { projection areas of } \\
\text { the concrete base }\end{array}$ \\
\hline 1 & 2 & 3 & 4 \\
\hline 1 & $\begin{array}{c}\text { ETAG } 001 \\
\text { [11] }\end{array}$ & $\begin{array}{l}\qquad N=N_{R k, c}^{0} \frac{A_{c, N}}{A_{c, N}^{0}} \cdot \psi_{s, N} \cdot \psi_{r e, N} \cdot \psi_{e c, N}, \\
N_{R k, c}^{0} \text { - the nominal resistance force of the anchor during } \\
\text { destruction from base concrete pulling, } \mathrm{H} ; \\
\psi_{s, N} ; \psi_{r e, N} ; \psi_{e c, N}-\text { coefficients that take into account the } \\
\text { uneven distribution of stresses in concrete, the probability of } \\
\text { splitting of the concrete base when pulling the anchor and } \\
\text { the effect of joint work of a group of anchors, respectively; } \\
A_{c, N} \text { - projection area of the prism for the anchoring group, } \\
\mathrm{mm}^{2}\end{array}$ & $\begin{array}{l}\quad A_{c, N}^{0}=9 h_{e f}^{2}, \\
h_{e f}-\text { anchoring } \\
\text { effective length, } \\
\mathrm{mm}\end{array}$ \\
\hline 2 & $\begin{array}{c}\text { Recommen- } \\
\text { dations } \\
{[8]}\end{array}$ & $\begin{array}{l}\qquad N \leq \frac{\phi_{2} \phi_{3} A R_{b t}}{1+3.5 \frac{e_{1}}{a_{1}}+3.5 \frac{e_{2}}{a_{2}}}, \\
R{ }_{b t}-\text { the concrete strength of concrete, MPa; } \\
e_{1} \text { и } e_{2}-\text { the eccentricities of the force } N \text { relative to the center } \\
\text { of gravity of the } A \text { area in the direction } a_{1} \text { и } a_{2} \text {, respectively, } \\
\mathrm{mm} \text {; } \\
a_{1} \text { и } a_{2} \text { - dimensions of the breakout projection surface, mm; } \\
\varphi_{2}-\text { coefficients taking into account the type of concrete ( } 0.5 \\
\text { is taken for heavy concrete); } \\
\varphi_{3}-\text { coefficients which are taken depending on the value of } \\
\text { stresses in the surrounding concrete }\end{array}$ & $A=4 h_{e f}^{2}$ \\
\hline
\end{tabular}




\begin{tabular}{|c|c|c|c|}
\hline 1 & 2 & 3 & 4 \\
\hline 3 & $\begin{array}{c}\text { ACI 318-19 } \\
{[10]}\end{array}$ & $\begin{array}{l}\qquad N=\frac{A_{N_{c}}}{A_{N_{c 0}}} \cdot \psi_{e d, N} \cdot \psi_{c, N} \cdot \psi_{c p, N} \cdot N_{b}, \\
N_{b}-\text { the basic tear tensile strength of concrete for one } \\
\text { anchor, taking into account the probability of cracks in the } \\
\text { base concrete, N: } \\
\text { at } h_{e f}<11 \text { inches - } \\
\qquad N_{b}=24 \cdot \lambda_{a} \cdot \sqrt{f_{c}^{\prime}} \cdot h_{e f}^{1.5}, \\
\text { at } 11 \leq h_{e f} \leq 25 \text { inches - } \\
\qquad N_{b}=16 \cdot \lambda_{a} \cdot \sqrt{f_{c}^{\prime}} \cdot h_{e f}^{5 / 3} ; \\
\quad-\text { coefficients that take into } \\
\psi_{e c, N} ; \psi_{e d, N} ; \psi_{c, N} ; \psi_{c p, N}-{ }_{\text {account, respectively, the eccentric application of a tearing }} \\
\text { force, edge effects, the presence of cracks in the anchor base, } \\
\text { as well as the probability of destruction from splitting } \\
\text { concrete when installing anchors into the finished base; } \\
A_{N_{c 0}}-\text { pull-out prism projection area for the anchoring } \\
\text { group, mm }{ }^{2}\end{array}$ & $A_{N c}=9 h_{e f}^{2}$ \\
\hline 4 & $\begin{array}{c}\text { Methodical } \\
\text { Aids } \\
\text { [7] }\end{array}$ & $\begin{array}{l}\qquad N_{u l t, c}=\frac{N_{n, c}^{0}}{\gamma_{b t} \cdot \gamma_{N c}} \frac{A_{c, N}}{A_{c, N}^{0}} \cdot \psi_{s, N} \cdot \psi_{r e, N} \cdot \psi_{e c, N} \cdot \psi_{M, N} \text {, } \\
N_{n, c}^{0}-\text { the value of the resistance force for a single anchor } \\
\text { located at a considerable distance from the edge of the } \\
\text { base and the adjacent anchor, in case of destruction from } \\
\text { base concrete breakout, N; is determined by tables } 8.6- \\
8.7[11] \text { or by the formula: } \\
\qquad N_{n, c}^{0}=k_{1} \cdot \sqrt{R_{b, n}} \cdot h_{e f}^{1.5}, \\
\gamma_{b t}-\text { the tensile strength reliability coefficient for } \\
\text { concrete, taken as } 1.5 \text {; } \\
\gamma_{N c}-\text { coefficient of the anchor working conditions when } \\
\text { pulling out the base concrete under tension, taken equal } \\
\text { to } 1.0 \text { for reinforcing bars; } \\
A_{c, N}^{0}-\text { the area of the square base of the conventional } \\
\text { breakout prism for a single anchor located at a } \\
\text { considerable distance from the edge of the base and the } \\
\text { adjacent anchor, mm }{ }^{2} \text {; } \\
A_{c, N}-\text { the actual base area of the conventional breakout } \\
\text { prism, taking into account the influence of adjacent } \\
\text { anchors, as well as the influence of the edge location, } \\
\text { mm }{ }^{2} ; \\
\Psi_{s, N}, \Psi_{r e, N}, \Psi_{e c, N}, \Psi_{M, N}-\text { coefficients that take into account } \\
\text { the effect of installation at the edge of the base, the effect } \\
\text { of installation of densely reinforcing structures in the } \\
\text { protective layer, the effect of eccentricity of the } \\
\text { application of forces in the anchor group, the effect of the } \\
\text { compression force and the action of the momentum, } \\
\text { respectively }\end{array}$ & $A_{c, N}^{0}=9 h_{e f}^{2}$ \\
\hline
\end{tabular}

The analysis of the calculated dependencies for determining the bearing capacity and the area of the lower base of the breakout pyramid as applied to mechanical anchors showed differences in their definition and requires further study. It should be noted that the 
regulatory documents and the few published studies available do not provide information on the form of destruction of samples from breakout.

\section{Numerical simulation}

In order to obtain data on the magnitude and direction of stresses and strains in a concrete element subject to a local tensile force transmitted by means of breaking out an anchor buried in a concrete body, data on the peculiarities of the formation and development of cracks in elements of this type, namely, the angle of crack propagation, a numerical simulation by the finite element method (FEM) of a reinforced concrete element with a single anchor was carried out [5].

The simulation was carried out in the environment of the "Abaqus/CAE» computing complex. The object of mathematical modeling is a prismatic concrete element with an anchor. The geometrical dimensions of the concrete prism are taken according to the requirements set forth in $[8,11,10,7]$, so that the height of the prism $h$ is $100 \mathrm{~mm}$ greater than the embedment depth of the anchor $h_{e f}$ (anchoring), and the distance from the anchor axis to the edge of the concrete element is not less than $1.5 h_{e f}$. In the body of the concrete prism, there is a smooth profile steel anchor with a diameter of $d=20 \mathrm{~mm}$, which has a reinforcement at the end in the form of a washer. The dimensions of the washer were assigned based on the requirements for the anchor embedment depth in order to avoid creasing the concrete over the washer [6]. The class of concrete of the prism was taken $\mathrm{C}^{20} / 25$, the anchor was modelled from an ideally elastic material with Young's modulus (modulus of elasticity) $\mathrm{E}_{\mathrm{s}}=2 \cdot 10^{5} \mathrm{MPa}$. The geometric characteristics of the simulated concrete prism and anchor are shown in Figure 2.

a)



b)

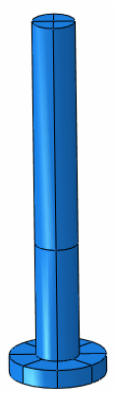

c)

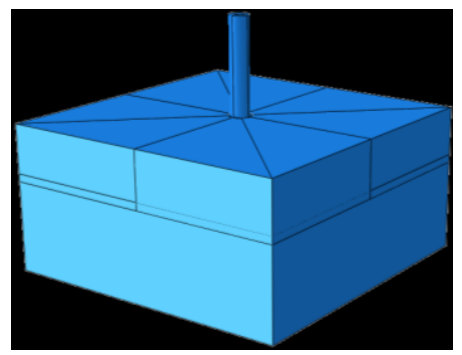

$\mathrm{a}$ - design scheme; $\mathrm{b}$ - general anchor model; $\mathrm{c}$ - general view of the modeled system

Fig. 2. Simulation system.

When placing the anchor in the body of the concrete base, the structural requirements for the thickness of the concrete base and its minimum strength characteristics, as well as the requirements for the dimensions of the surface of the concrete base for the elimination of the influence of the edge effect and adjacent anchors, based on the expected type of destruction of the system under consideration from the action of tensile force, namely from breaking out the base concrete, in accordance with clause 8.1.3.4 of the recommendations [7] (Figure 2).

A fracture model to simulate artificial stone material (concrete) was used. The advantage of this model is the probability of taking into account the formation and development of cracks not only during tension, but also during compression and shear, which is especially important in the presence of a tensile force applied to the anchor, since there is a probability of creasing the base concrete under the washer. 
The interaction between the anchor and the concrete was described by setting the corresponding characteristics of the contact of the surfaces of two materials by means of an intermediate layer with a thickness of $2 \mathrm{~mm}$. The characteristics of the intermediate layer were set in such a way that it worked elastically till the moment of traction failure, and after the contact between the concrete and the anchor broke, the intermediate layer was turned off from work and did not transfer efforts onto the surrounding concrete. The intermediate layer is rigidly connected to both the concrete base and the anchor. The pliability of the joint was ensured by the characteristics of the intermediate layer.

When specifying the computational model, the spacing is adopted in such a way as to ensure a convergence to analytical solution $[1,4]$. For this, at least 5 finite elements (FE) were taken according to the effective (working) anchorage length $h_{e f}$. The mesh must meet certain 'quality' parameters that determine the accuracy of the calculations, too.

The modeling of the supports was carried out by a simplified method: the prohibition of vertical shifts along the lower face of the concrete base (rigid fastening). Loadings were carried out by uniform displacement of the anchor butt-end. The force arising in the anchor was determined by the magnitude of the stresses in the anchor at a given value of displacement.

The results of modelling the stress-strain state of a concrete prism under the action of a tensile force on an anchor located in the concrete body, with an anchor embedment depth of $150 \mathrm{~mm}$, is shown in Figure 3.
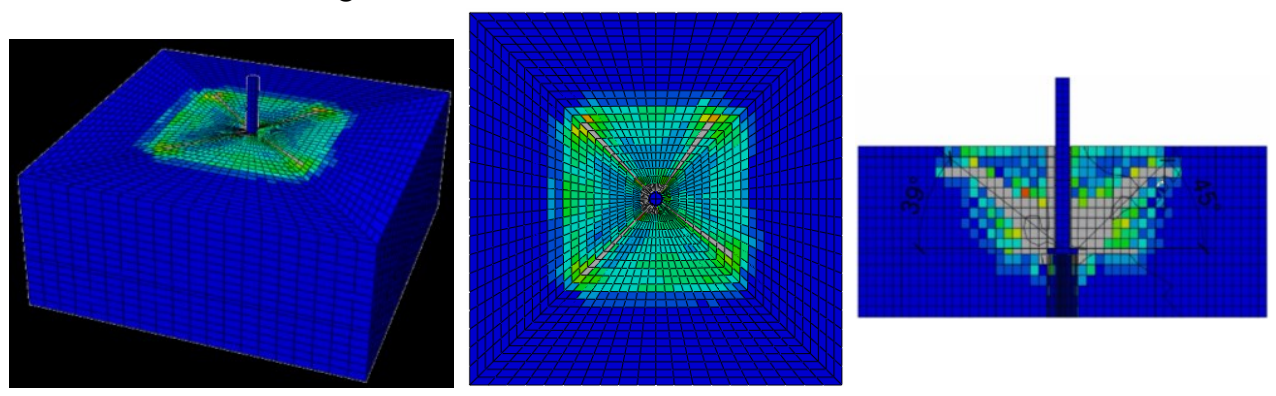

Fig. 3. Breaking out the concrete of the base under the action of a tensile force on the anchor at the embedment depth $h_{\mathrm{ef}}=150 \mathrm{~mm}$.

\section{Results and Discussion}

The results of numerical modeling, as well as the data calculated according to the design models considered in Table 1, with an anchor embedment depth $h_{\text {ef }}$ from 50 to $400 \mathrm{~mm}$ with spacing of $50 \mathrm{~mm}$, are presented in Table 2 .

The analysis of the results of numerical modelling showed that all samples are destroyed with the formation of a pyramid, the top of which is located at the point of action of the resultant force of breakout effort.

For all numerical models, the process of destruction of the simulated concrete base from the action of a tensile force applied to the anchor begins with the inclusion of an intermediate layer in the work, which itself is the contact zone of two materials. At an embedment depth of $100 \mathrm{~mm}$ or more, at the moment when the stresses in the intermediate layer reach their limit values, the growth of stresses in concrete slows down. On the graph of the dependence of stresses in concrete from displacements, the moment of termination of the work of the intermediate layer is characterized by a fracture, followed by a horizontal section (Figure 4), characterized by a redistribution of forces between the intermediate layer and concrete over the reinforcement of the anchor. 
Table 2. Resistance of the anchor at destruction from the base concrete breakout.

\begin{tabular}{|c|c|c|c|c|c|c|c|c|c|c|c|}
\hline \multirow{2}{*}{$\begin{array}{c}\text { Experi- } \\
\text { mental } \\
\text { model } \\
\text { No. }\end{array}$} & \multirow{2}{*}{$\begin{array}{c}\text { Effective } \\
\text { anchorage } \\
\text { depth } \\
h_{\text {ef }}, \text { мм }\end{array}$} & \multicolumn{5}{|c|}{ Breakout force $\mathrm{N}, \mathrm{kN}$} & \multicolumn{5}{|c|}{$\begin{array}{l}\text { Angle of inclination of cracks to the } \\
\text { anchor axis / the angle of inclination of } \\
\text { cracks to the reinforcement face }\end{array}$} \\
\hline & & [11] & [8] & {$[10]$} & [7] & $\begin{array}{l}\text { «Abaqus/ } \\
\text { CAE» } \\
\text { Model }\end{array}$ & [11] & [8] & {$[10]$} & [7] & $\begin{array}{l}\text { «Abaqus } \\
\text { CAE» } \\
\text { Model }\end{array}$ \\
\hline 1 & 50 & 14,2 & 10,6 & 9,4 & 10,4 & 17,1 & $34^{\circ} / 44^{\circ}$ & $32^{\circ} / 45^{\circ}$ & $27^{\circ} / 35^{\circ}$ & $63^{\circ} / 54^{\circ}$ & $35^{\circ} / 45^{\circ}$ \\
\hline 2 & 100 & 40,1 & 42,4 & 26,5 & 45,1 & 52,1 & $34^{\circ} / 38^{\circ}$ & $38^{\circ} / 45^{\circ}$ & $31^{\circ} / 35^{\circ}$ & $60^{\circ} / 55^{\circ}$ & $37^{\circ} / 43^{\circ}$ \\
\hline 3 & 150 & 73,6 & 95,4 & 48,7 & 77,4 & 97,9 & $34^{\circ} / 37^{\circ}$ & $40^{\circ} / 45^{\circ}$ & $32^{\circ} / 35^{\circ}$ & $59^{\circ} / 56^{\circ}$ & $39^{\circ} / 45^{\circ}$ \\
\hline 4 & 200 & 113,4 & 169,7 & 75,1 & 114,3 & 160,3 & $34^{\circ} / 36^{\circ}$ & $41^{\circ} / 45^{\circ}$ & $33^{\circ} / 35^{\circ}$ & $59^{\circ} / 56^{\circ}$ & $41^{\circ} / 45^{\circ}$ \\
\hline 5 & 250 & 158,4 & 265,1 & 104,9 & 155,3 & 235,1 & $34^{\circ} / 36^{\circ}$ & $41^{\circ} / 45^{\circ}$ & $33^{\circ} / 35^{\circ}$ & $59^{\circ} / 56^{\circ}$ & $43^{\circ} / 45^{\circ}$ \\
\hline 6 & 300 & 208,3 & 381,7 & 123,9 & 200,1 & 309,4 & $34^{\circ} / 36^{\circ}$ & $41^{\circ} / 45^{\circ}$ & $33^{\circ} / 35^{\circ}$ & $58^{\circ} / 55^{\circ}$ & $43^{\circ} / 45^{\circ}$ \\
\hline 7 & 350 & 262,5 & 519,6 & 246,4 & 248,2 & 436,5 & $34^{\circ} / 36^{\circ}$ & $41^{\circ} / 45^{\circ}$ & $33^{\circ} / 35^{\circ}$ & $58^{\circ} / 55^{\circ}$ & $41^{\circ} / 45^{\circ}$ \\
\hline 8 & 400 & 320,7 & 678,7 & 277,4 & 299,6 & 659,9 & $34^{\circ} / 36^{\circ}$ & $41^{\circ} / 45^{\circ}$ & $33^{\circ} / 35^{\circ}$ & $58^{\circ} / 54^{\circ}$ & $41^{\circ} / 45^{\circ}$ \\
\hline
\end{tabular}

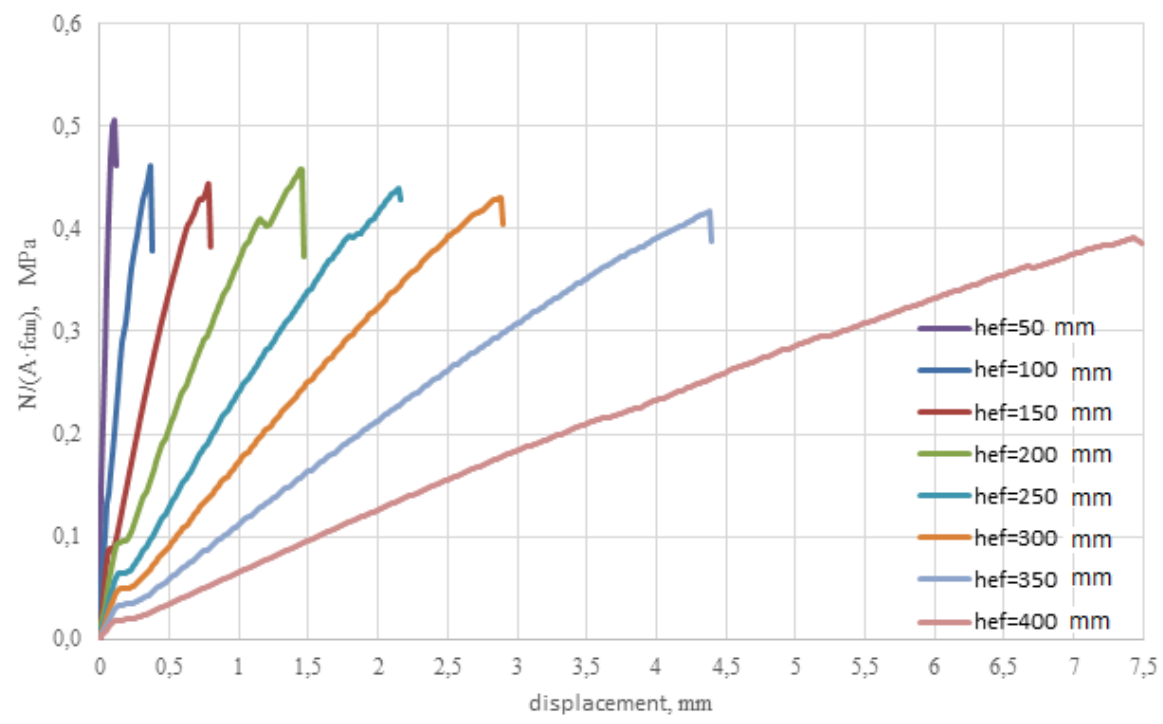

Fig. 4. Dependences of stresses in concrete on the length of the anchor.

Further perception of tensile force by concrete due to work in the contact zone with the washer is shown in the diagram as an ascending branch following the horizontal section. The appearance of a descending branch on the graph, corresponding to a drop in the force in the anchor, indicates the destruction of the concrete base.

The nature of the appearance and development of cracks that form in the concrete base during tensile work differs depending on the depth of application of the tensile force. The appearance of slanting cracks, propagating from the anchor washer to the concrete surface, is typical for all experimental models. However, only at a depth of of 50 and $100 \mathrm{~mm}$ application of a tensile force, cracks breaking out the base concrete come out to the surface of the concrete prism at the moment the anchor reaches its maximum tensile effort. At an 
anchor embedment depth of $150 \mathrm{~mm}$ or more, tear cracks formed at the washer and propagating to the surface of the concrete base, at the limit value of the tensile force, do not come out to the surface, and destruction in this case occurs due to the splitting of the concrete breakout prism formed by slanting cracks. The appearance of cracks on the concrete surface of the base, propagating from the resultant of the breakouting out effort to the projection angles of the breakout prism, is typical for all simulated specimens, but only at a depth of application of a tensile force of more than $150 \mathrm{~mm}$, does this lead to the destruction of the specimen, and at a smaller embedment depth this is a consequence of pulling out.

The slant angle of cracks in concrete, which are formed from the top of the breakout pyramid and propagating to the surface, differs depending on the depth of application of the resultant breakout force. With an increase in the anchor length, the slant angle of cracks increases from $35^{\circ}$ to $43^{\circ}$.

The analysis of the stress isofields in concrete showed that with an increase in the depth of application of the tensile force, there is a decrease in the maximum stresses in concrete from the action of a tensile effort on the anchor from $0.51 \mathrm{MPa}$ to $0.39 \mathrm{MPa}$. Gradual decrease in stresses along the surface of the projection of the breakout prism is conditioned by a more uniform distribution of stresses due to an increase in the surface area of the breakout prism.

Comparison of the destructive forces obtained from the results of numerical and analytical modeling at the depths of application of the tensile effort from 50 to $400 \mathrm{~mm}$ with a spacing of $50 \mathrm{~mm}$ and the calculations made according to the design models given in Table 1 is shown in Figure 5.

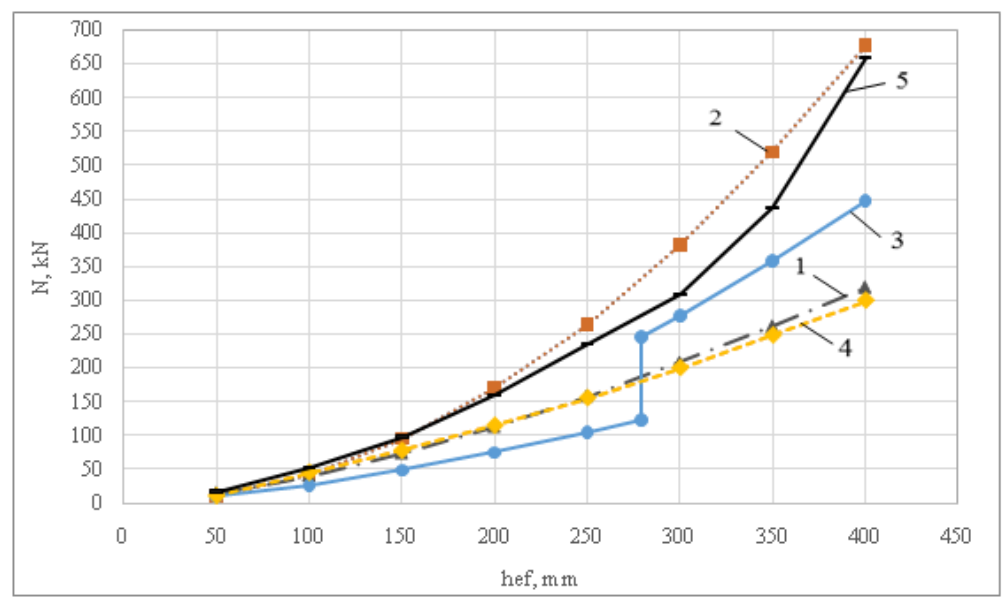

1 - ETAG 001 [11]; 2 - Recommendations [8]; 3 - ACI 318-19 [10]; 4 - according to the methodological manual [7]; 5 - destruction effort obtained from the results of numerical and analytical simulation

Fig. 5. Comparison of the dependence of the breakout resistance on the depth of application of the tensile force $h_{e f}$, obtained from computational models and from the results of numerical-analytical modeling.

The comparison of the results reflected in Figure 6 showed that the dependence of the breakout resistance on the depth of application of the tensile force, obtained as a result of numerical-analytical modeling, is in good agreement with the data obtained in the calculation according to the norms [8]. 


\section{Conclusions}

Based on the results of numerical modelling of the operation of a concrete element under the action of a point applied tensile force, implemented by means of an anchor buried in the concrete body, the following conclusions can be drawn:

1. The destruction of the concrete base has a different character depending on the depth of the application of the tensile effort. The formation of slant cracks, propagating from the anchor base to the concrete surface, is typical for all experimental models. At a depth of 50 and $100 \mathrm{~mm}$ of application of a tensile force, cracks breaking off the concrete of the base emerge on the surface of the concrete prism at the moment of destruction (at the maximum tensile force). At a depth of application of a tensile force of $150 \mathrm{~mm}$ or more, breakout cracks starting at the base of the anchor, with a destruction effort, do not come to the surface. The destruction in this case occurs due to the splitting of the concrete prism formed by breakout cracks.

2. The angle of slant cracks, propagating from the point of application of the tensile effort and forming a breakout prism, differs depending on the depth of application of the force: with the increase in the anchor length there occurs an angle increase from $35^{\circ}$ to $43^{\circ}$. The slant angle of cracks extending from the lateral facet of the anchor reinforcement is about $45^{\circ}$ for the all considered cases.

3. For stresses in concrete, which are formed on the surface of the projection of the breakout prism, there is a tendency to decrease as the depth of application of the tensile force increases, which is a consequence of a more uniform distribution of stresses over the surface of the breakout prism, which can be explained by the 'scale factor' described by Bazant [7].

4. The dependence of the breakoff resistance on the depth of application of the tensile force, obtained as a result of numerical-analytical modeling, is in good agreement with the data obtained in the calculation according to the norms [8].

\section{References}

1. Bate, K. Numerical Methods of Analysis and the Finite Element Method / K. Bate, E. Wilson. - M.: Stroyizdat, 1982. - 448 p.

2. Concrete and Reinforced Concrete Structures: SP 5.03.0920. - Introduction. 11/16/2020. - Minsk: Ministry of Architecture and Construction. RB, 2020. - 244 p.

3. Golyshev, A. B. Design of Reinforced Concrete Structures: Reference Book / A. B. Golyshev [and others]; ed. A. B. Golyshev. - 2nd ed. - K.: Budivelnyk, - 1990. $-544 \mathrm{p}$.

4. Zenkevich, O. The Finite Element Method in the Theory of Structures and in Mechanics of Continuous Environment / O. Zenkevich, I. Chang. - M.: Nedra, 1974. $-240 \mathrm{p}$.

5. Lukin, A.V. Finite Element Modelling and Analysis of the Stress-Strain State of Reinforced Concrete Structures / A. V. Lukin, V.S. Modestov // Scientific and Technical Statements of SPbSPU. - 2014. - № 3 (201): Physics and Mathematics. P. 35 - 46 .

6. Metal structures / AB Shurin [and others]; Edit. A. B. Shurin. - Brest: BrSTU Publishing, 2020. - $177 \mathrm{p}$.

7. Methodological Guide for the Design of Steel Embedded Parts for Reinforced Concrete Elements: Approved by the Ministry of Construction and HousingCommunal Services of the Russian Federation. - M., 2019. - 98 p. 
8. Recommendations for the design of steel embedded parts for reinforced concrete structures / NIIZhB. - M.: Stroyizdat, - 1978. - 87 p.

9. Shalobyta, N. N. Analysis of Methods for Calculating the Strength of Elements of Reinforced Concrete Structures for Pull-off. Shalobyta, E. S. Matveenko, T. P. Shalobyta, N. V. Matveenko // Bulletin of Brest State Technical University. 2021. - № 1 (124): Construction and Architecture. - P. 39 - 42.

10. Building Code Requirements for Structural Concrete (ACI 318-19) and Commentary (318R-19): ACI Committee 318 - MI; Farmington Hills: American Concrete Institute, 2019. $-628 \mathrm{p}$.

11. Guideline for European Technical Approval of Metal Anchors for Use in Concrete: ETAG 001: 2008. - Brussels: European Organization for Technical Approvals, Introduced February 2008. - 34 p. 